\title{
Micro, klein, middelgroot en groot
}

\section{Ruud Vergoossen}

Sinds jaar en dag kennen we op grond van Titel 9 BW 2 de indeling van ondernemingen in klein, middelgroot en groot. Deze indeling is een uitvloeisel van de Vierde EEG-richtlijn. De wetgever verleent aan kleine en middelgrote ondernemingen een aantal vrijstellingen ten aanzien van de inrichting en publicatie van de

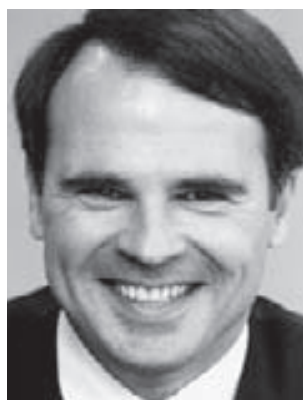
jaarstukken. Daarbij gelden met name voor kleine ondernemingen extra vrijstellingen ten aanzien van de publicatie-eisen. Zij hoeven slechts een gecomprimeerde balans met toelichting te deponeren bij het handelsregister. Bovendien zijn kleine ondernemingen vrijgesteld van de verplichte accountantscontrole.

De Europese Commissie is van plan om in het kader van de administratieve lastenverlichting voor het midden- en kleinbedrijf de indeling in groottecategorieën op de schop te nemen. Op 10 juli jongstleden heeft zij een mededeling naar buiten gebracht met voorstellen voor 'een vereenvoudiging van het ondernemingsklimaat.'

Deze voorstellen hebben onder meer betrekking op de financiële verslaggeving en de jaarrekeningcontrole. De Europese Commissie komt ten behoeve van het midden- en kleinbedrijf met de volgende maatregelen:

- het naast de bestaande categorieën van grote, middelgrote en kleine ondernemingen invoeren van de categorie 'micro-ondernemingen';

- een verlicht overgangsregime bij overschrijding van de drempels voor kleine en middelgrote ondernemingen;

- de volledige vrijstelling van de publicatieplicht voor kleine ondernemingen;

Prof.dr. R.G.A. Vergoossen RA is directeur Vaktechniek van BDO Campsobers Accountants \& Adviseurs en hoogleraar op het gebied van de externe financiële verslaggeving aan Nyenrode Business Universiteit en Universiteit Maastricht.
- een uitbreiding van de vrijstellingen voor ondernemingen zonder specifieke externe gebruiker van hun financiële verslaggeving.

Ik zal deze maatregelen hieronder kort toelichten.

Micro-ondernemingen zijn bijzonder kleine ondernemingen met minder dan tien werknemers, een balanstotaal van minder dan $€ 500.000$ en/of een omzet van minder dan $€ 1$ miljoen (zie tabel). Op grond van de voorstellen van de Europese Commissie zouden deze ondernemingen in Nederland volledig kunnen worden vrijgesteld van het opmaken van een jaarrekening in overeenstemming met Titel 9 BW 2. Op dit moment moet een kleine onderneming de voor een middelgrote onderneming geldende voorschriften met betrekking tot de inrichting en de publicatie van de jaarstukken toepassen en moet zij bovendien haar jaarrekening laten controleren door een accountant, zodra zij de drempel voor middelgrote ondernemingen twee jaar op rij overschrijdt. Voor middelgrote ondernemingen die de drempel voor grote ondernemingen overschrijden geldt dezelfde overgangsperiode. De Europese Commissie wil deze overgangsperiode optrekken naar vijf jaar. Dit betekent dus dat zodra een kleine onderneming middelgroot wordt, zij nog vijf jaar lang kan profiteren van de vrijstellingen die gelden voor kleine ondernemingen. Verder is het de bedoeling dat in de omgekeerde situatie - dus bijvoorbeeld wanneer een middelgrote onderneming klein wordt of een grote onderneming middelgroot - de overgangsperiode juist wordt verkort van twee tot één jaar. Zodoende kunnen ondernemingen die niet meer voldoen aan de drempels eerder profiteren van de vrijstellingen.

De Europese Commissie stelt voor om de publicatieplicht voor kleine ondernemingen af te schaffen, omdat de jaarrekening van deze ondernemingen slechts wordt gebruikt door een beperkt aantal belanghebbenden - zoals bankiers - die de betrokken ondernemingen rechtstreeks om de benodigde financiële informatie kunnen verzoeken.

Ook zouden volgens de Europese Commissie minder eisen kunnen worden gesteld aan ondernemingen die maar weinig externe gebruikers van hun jaarrekening 
Tabel: Indelingscriteria micro-ondernemingen, kleine, middelgrote en grote ondernemingen (bedragen in miljoenen $€$ )

\begin{tabular}{|l|l|l|l|l|}
\hline Indelingscriteria & Micro & Klein & Middelgroot & Groot \\
\hline Waarde activa & $<€ 0,5$ & $\geq € 0,5$ en $\leq € 4,4$ & $>€ 4,4$ en $\leq € 17,5$ & $>€ 17,5$ \\
Netto-omzet & $<€ 1,0$ & $\geq € 1,0$ en $\leq € 8,8$ & $>€ 8,8$ en $\leq € 35,0$ & $>€ 35,0$ \\
Aantal werknemers & $<10$ & $\geq 10$ en $<50$ & $\geq 50$ en $<250$ & $\geq 250$ \\
\hline
\end{tabular}

Noten:

- een onderneming behoort tot de categorie klein, middelgroot of groot als aan twee van de drie criteria wordt voldaan. Uit de mededeling van de Europese Commissie blijkt niet of zij een dergelijke systematiek ook voor micro-ondernemingen voor ogen heeft of dat die zouden kunnen volstaan met het voldoen aan één van de drie criteria;

- de criteria gelden niet voor beursgenoteerde ondernemingen, beleggingsmaatschappijen, banken en verzekeringsmaatschappijen. Zij zullen steeds moeten voldoen aan de eisen die voor 'groot' gelden.

hebben. Zij wil hier een risicogeoriënteerde benadering volgen, waarbij bijvoorbeeld middelgrote ondernemingen met leiding en eigendom in één hand het regime dat geldt voor kleine ondernemingen mogen toepassen.

Naast de hiervoor besproken maatregelen, onderzoekt de Europese Commissie ook nog - onder meer de mogelijkheid om de controleplicht voor middelgrote ondernemingen af te schaffen, het gebruik te vergroten van de groepsvrijstellingsregeling (in Nederland ex artikel 403 BW 2) door dochtermaatschappijen die tot een groep behoren, het voor kleine en middelgrote ondernemingen afschaffen van de verplichting om rekening te houden latente belastingen en het beperken van de informatie die moet worden opgenomen in de toelichting.

De Europese Commissie wil tevens 'verduidelijken' of beursgenoteerde ondernemingen met uitsluitend dochtermaatschappijen die van te verwaarlozen betekenis zijn onder de Europese IAS-verordering vallen en dus een jaarrekening op basis van IFRS moeten opstellen. Het is evident dat het afschaffen van de consolidatieplicht of van de plicht om een IFRS-jaarrekening op te maken voor deze ondernemingen tot een aanzienlijke lastenverlichting kan leiden.

De maatregelen die de Europese Commissie voorstelt, dienen wat mij betreft van harte te worden ondersteund en nader te worden uitgewerkt. In dat kader beschouwd, is het vreemd dat de Nederlandse regering nu komt met een wetsvoorstel om de jaarrekening van kleine ondernemingen te laten samenvallen met de fiscale vermogensopstelling en winstberekening. ${ }^{2}$ Het lijkt mij beter dat zij een dergelijk wetsvoorstel aanhoudt totdat duidelijk is in hoeverre de voorstellen van de Europese Commissie door de lidstaten en het Europese parlement worden ondersteund.

Overigens betwijfel ik of het wetsvoorstel daadwerkelijk leidt tot de beloofde administratieve lastenverlichting van ten minste $€ 400$ miljoen. Daarnaast kan toepassing van de 'samenvalmogelijkheid' zonder aanpassingen in het bestaande jaarrekeningrecht leiden tot complicaties. ${ }^{3}$ Bijvoorbeeld wat te doen als de belastingaangifte door de fiscus wordt gecorrigeerd nadat de jaarrekening van de onderneming al door de aandeelhoudersvergadering is vastgesteld? Dat is toch iets wat geregeld voorkomt. De jaarrekening kan dan niet zonder meer worden aangepast, waardoor de cijfers in beide documenten toch weer gaan divergeren.

Ook de discussie die momenteel driftig wordt gevoerd over een IFRS voor het midden- en kleinbedrijf moet in het kader van de administratieve lastenverlichting worden beschouwd. ${ }^{4}$ In mijn optiek zal een dergelijke IFRS - die toch een afgeleide is van de vaak complexe standaarden die gelden voor de beursgenoteerde ondernemingen - eerder tot hogere dan lagere administratieve lasten voor het midden- en kleinbedrijf leiden en verdient dan ook niet zonder meer navolging. ${ }^{5}$ De Europese Commissie formuleert het in haar mededeling heel diplomatiek door te stellen dat na een eerste analyse zij niet gelooft 'dat de lopende IASB-werkzaamheden met betrekking tot de financiële verslaggeving door het MKB volstaan om het leven van Europese kleine en middelgrote ondernemingen te vergemakkelijken' (pag. 9).

\section{Noten}

1 Zie Commissie van de Europese Gemeenschappen, Mededeling van de commissie over een vereenvoudiging van het ondernemingsklimaat op het gebied van vennootschapsrecht, financiële verslaggeving en controle van jaarrekeningen, Brussel, 10 juli 2007.

2 Dit wetsvoorstel lag ten tijde van het schrijven van deze column voor advies bij de Raad van State en was derhalve nog niet door de regering ingediend bij de Tweede Kamer (zie persbericht Rijksvoorlichtingsdienst d.d. 1 juni 2007, Kabinet: lasten bedrijfsleven verder omlaag).

3 Zie R.G.A.Vergoossen, Lastenverlichting voor $\mathrm{mkb}$ is een farce, Het Financieele Dagblad, 12 juni 2007, p. 9; R.G.A. Vergoossen, Kostenbesparing, Het Financieele Dagblad, 19 juli 2007, p. 7.

4 Zie International Accounting Standards Board, Exposure Draft of a proposed International Financial Reporting Standard for Small and Medium-sized Entities, februari 2007.

5 Zie R.G.A. Vergoossen, IFRS is onnodig voor het mkb, Het Financieele Dagblad, 19 oktober 2006, p. 11. 